\title{
Finite Element Approach to Stress Analysis for Failure Prediction of a Six DOF Hybrid Kinematic Machine for On-Site Machining
}

\author{
Maxwell Zvikomborero Sakutukwa ${ }^{1}$, Anshul Jain ${ }^{2}$ \\ ${ }^{1,2}$ Department of Mechanical Engineering, ITM University, NH-75 Jhansi road, Gwalior, MP, India
}

\begin{abstract}
This paper presents an approach for stress analysis of a six DOF hybrid kinematic machine for on-site machining. The finite element method is used in conducting the stress analysis. The main objective of the analysis is to predict component failure through analysis of stress distribution within the components of the entire hybrid kinematic machine. The procedure for applying finite element analysis as a numerical technique for solving complex engineering problems is outlined. The basic concept of the Von Mises theory of failure is also discussed in a bid to give an insight of the approach being utilized by the simulation software. The procedure for carrying out the finite element analysis is presented as comprising of three main stages (1) the pre-processing stage, (2) the solving stage and (3) the post processing stage. The simulation was conducted several times at different configurations until the convergence criteria were satisfied. Finally reports were generated and results for stresses, strain, displacements and factor of safety are presented.
\end{abstract}

Keywords: Finite Element Analysis, Stress Analysis, Hybrid Kinematic machine, Autodesk Inventor, On-site machining

\section{Introduction}

The most common cause of component failure in machine theory is stress induced in the component due to applied forces or heat. Finite element method is a very powerful tool for numerical solution to many engineering problems including stress analysis, flux and flow problems [1]. The fundamental of the finite element method is to discretize a complex region defining a continuum into simple geometric shapes [2], [7]. All the considerations are done on a simple shape called an element. The elements are then assembled together considering the boundary conditions in order to obtain a set of equations which can be solved to obtain an approximate behavior of the system under consideration [2]. Several methods are available for FEA including the Rayleigh-Ritz method, the Galerkin's method and the principle of virtual work. These are approximate solution methods which make use of the potential energy or the variational methods [2]. In the $21^{\text {st }}$ century, computer technology dominated the engineering field hence CAD systems are now available for finite element analysis. The only challenge is for the users to understand the underlying principles upon which the software being used is operating on. Researchers must understand the theory of failure being applied by the software as well as the finite element method being employed. A variety of software are available on the market, several researchers have modeled and analyzed their designs in Solidworks, ANSYS and Autodesk Inventor among other software. In this paper, stress analysis for a six DOF hybrid kinematic machine for on-site machining is presented through the finite element approach using Autodesk Inventor software. The conceptual design of hybrid kinematic machine was discussed in [3]. For performance evaluation and failure prediction stress analysis is conducted in this work.

Organization of this paper: The next section presents the literature survey; section III outlines the static analysis procedure and its main stages. The results are presented in section IV then a brief discussion of the main observations is given in section $\mathrm{V}$.

\section{Literature Survey}

An exhaustive literature review on the design and analysis of different types of kinematic machines was conducted. In the past three decades several kinematic machines have been proposed by many researchers (Zhang 2013). Much effort has been directed towards the kinematic design and stiffness analysis of serial and parallel manipulators. Several researchers developed kinematic, kinetostatic and stiffness models which are being utilized by other researchers in the robotics research community [4], [5]. For hybrid kinematic machines very few researchers have proposed meaningful models due to the complex nature of the structure which is a combination of a serial and parallel structure. One interesting stiffness model was proposed by [5], however the proposed models focuses on the development of a stiffness matrix which can be used to evaluate the displacements, stress and strain for any applied end effector loads. A hybrid kinematic machine tool is one which incorporates the features of both the serial and the parallel kinematic machine tool structures [5]-[7]. Zhang (2015) employed the finite element method in analyzing a five DOF compliant hybrid micromanipulator using ANSYS software. The finite element analysis enables researchers to analyze their designs and eliminate weak points before committing resources to the design. The finite element analysis results will be useful in determining component life and areas of further improvement [6]. Finite element analysis is the best method for optimizing new designs, verifying the condition of existing systems, evaluating new concepts, performance evaluation and failure prediction [7]. "Using finite elements, complex partial differential equations that describe the behavior of structures can be reduced to a set of linear equations that can easily be solved using the standard techniques of matrix algebra"[7]. Finite element analysis can be used to virtually any engineering system. The only difference is the type of 


\section{International Journal of Science and Research (IJSR) \\ ISSN (Online): 2319-7064}

Index Copernicus Value (2013): 6.14 | Impact Factor (2015): 6.391

analysis to be conducted. Many software offers a variety of tools for finite element analysis which may include static analysis, flow analysis, dynamic analysis, explicitly dynamics, thermal analysis and many more.

\section{Static Analysis}

In this paper a static analysis is conducted on the six DOF hybrid kinematic machine using Autodesk Inventor software. This analysis is mainly focused on the stress distribution throughout the components of the hybrid structure. However strain cannot be left out in this analysis. The main objective is to observe the components which are subjected to excessive stress and find out which components are most likely going to fail due to stresses under the applied end effector loads. Table 1 presents the end-effector forces and moments which were calculated from conventional design formulas as discussed in [3].

Table 1: Maximum allowable end-effector loads

\begin{tabular}{|c|c|}
\hline Parameter & Value \\
\hline Force in $\mathrm{x}$ direction $\left(\mathrm{F}_{\mathrm{ex}}\right)$ & $525 \mathrm{~N}$ \\
\hline Force in $\mathrm{x}$ direction $\left(\mathrm{F}_{\mathrm{ey}}\right)$ & $525 \mathrm{~N}$ \\
\hline Force in $\mathrm{x}$ direction $\left(\mathrm{F}_{\mathrm{ez}}\right)$ & $500 \mathrm{~N}$ \\
\hline Torque about the tool axis & $7.86 \mathrm{Nm}$ \\
\hline
\end{tabular}

Most software including Autodesk Inventor operates on the basic principles of the Von Mises stress theory of failure. This theory states that failure will occur when the maximum shear strain energy exceeds the shear strain energy obtained by simple tensile test. This theory is also called the maximum shear strain energy theory or the distortion energy theory [9]. In most applications it is adopted because it is the most accurate among all the theories of failure and it gives very satisfactory results for ductile materials. This theory can be represented by a mathematical expression as:

$2 \sigma^{2}=\left(\sigma_{1}-\sigma_{2}\right)^{2}+\left(\sigma_{2}-\sigma_{3}\right)^{2}+\left(\sigma_{3}-\sigma_{1}\right)^{2}(1)$

Where $\sigma_{1}, \sigma_{2}$ and $\sigma_{3}$, are the three principle stresses at a point being considered and $\sigma$ is the elastic limit stress.

\subsection{Static Simulation Steps}

There are basically three main stages in any static simulation process. The first stage involves the preparation of the simulation by defining all relevant parameters. The second stage is the solving stage where the simulation is run. The last stage involves the analysis of results and making necessary changes in order to optimize the design.

\section{Pre-processing:}

1. Open assembly model in dynamic simulation environment

2. Set initial conditions of the model to the desired configuration

3. Export the model to FEA environment

4. Create simulation

5. Specify simulation properties

6. Assign materials to all components

7. Specify boundary conditions ( loads and constraints)

8. Generate mesh for the model

\section{Solving:}

9. Run the simulation

\section{Post-processing:}

10. View the Results.

11. Make necessary changes to refine the assembly.

12. Rerun the simulation to update the results.

13. Use result convergence and resolve to ensure that the results are as accurate as possible.

14. Repeat the process until you optimize the component.

15. Generate report

\subsection{Mesh Generation}

The results of any finite element analysis depend on the quality of meshing. In the simulation performed in this research, the free meshing technique was used. Free meshing is unstructured, flexible and has a complex topology. Quad, tri, tetra and hex are available mesh shapes for 3 dimensional elements in most software.

The static simulation begins with a number of mesh regeneration steps to make sure that the convergence criteria are satisfied. Fig 1 shows the 3D meshed model of the hybrid kinematic machine with tri shape elements and appropriate element size which gives admissible results. The forces and moments exerted by the work piece on the tool are also shown, however these are vectors which change direction depending on the motion of the tool hence the vector components input option must be utilized.

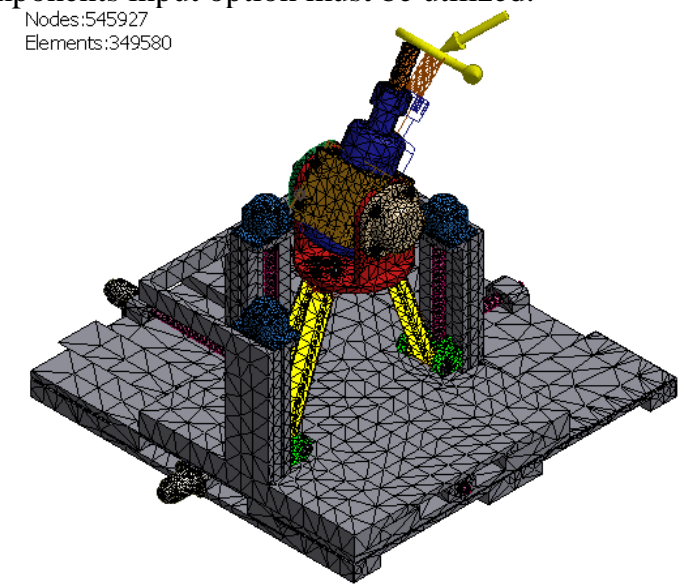

Figure 1: Mashed model of the hybrid kinematic machine

\section{Results}

After conducting stress analysis in various configurations of the hybrid kinematic machine, several reports were generated. The results were analyzed and the results of the configuration presented in Fig (2-5) attracted much attention since the results revealed that the structure has higher stress values in this configuration than the other configurations. Fig 2 (a-c) shows the distribution of Von Mises stress, $1^{\text {st }}$ principle stress and the $3^{\text {rd }}$ principle stress through out the machine structure. It can be observed that all the stress values are low enough to guarantee the reliability of the structure. The maxmum stress on the kinematic machine is due to the stress concentration on the shoulder of the cutting tool. The first principle stress on the tool shoulder is around 158.2MPa, however this stress is much lower than the values 


\section{International Journal of Science and Research (IJSR) \\ ISSN (Online): 2319-7064}

Index Copernicus Value (2013): 6.14 $\mid$ Impact Factor (2015): 6.391

which were obtained by Von Mises theory of failure form equation (4). Fig 3 shows the strain distribution thruoghout the kinematic structure. Strain is stress related though the relationship is complex for a complex structure like the hybrid kinematic structure.

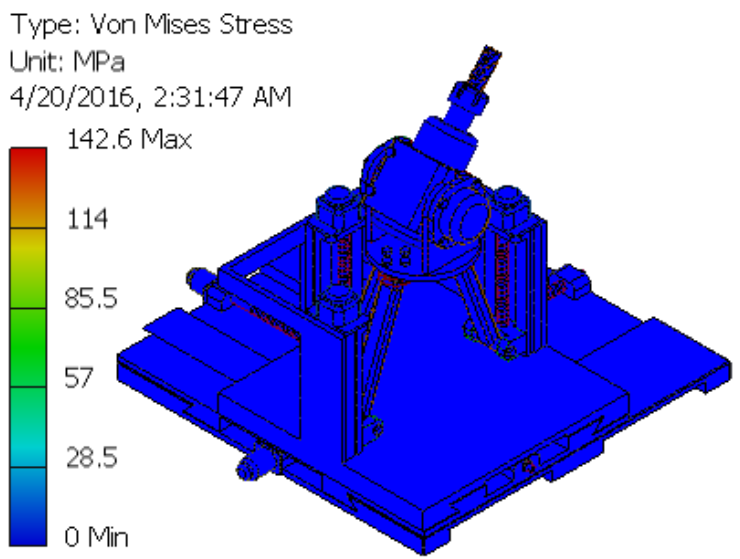

(a) Von Mises stress distribution

Type: 1st Principal Stress

Unit: $\mathrm{MPa}$

4/20/2016, 2:45:03 AM

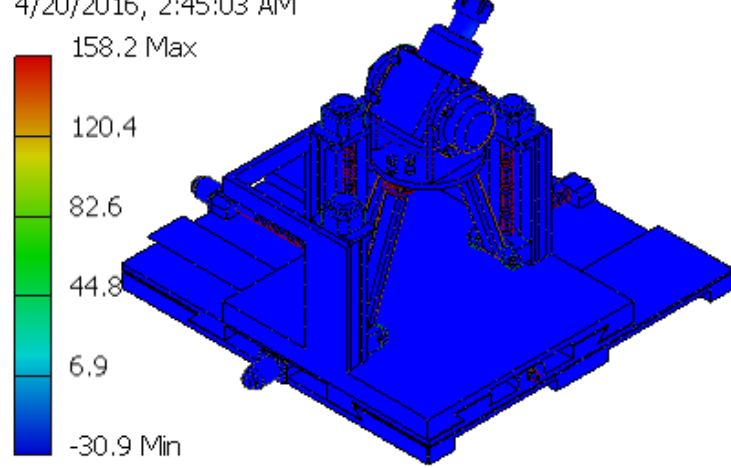

(b) First principle stress distribution

Type: 3rd Principal Stress

Unit: $\mathrm{MPa}$

$4 / 20 / 2016,2: 47: 48$ AM

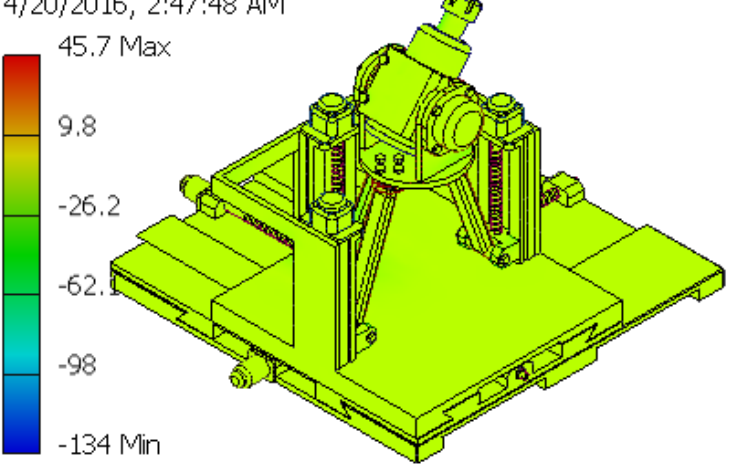

(c) Third principle stress distribution

Figure 2: Stress distribution on the hybrid kinematic machine
Type: Equivalent Strain

Unit: ul

4/20/2016, 2:53:22 AM

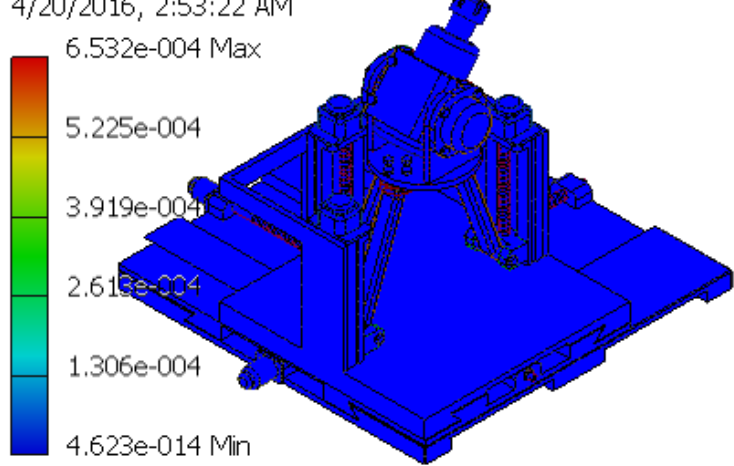

(a) Equivalent strain distribution

Type: 1st Principal Strain

Unit: ul

$4 / 20 / 2016,2: 55: 51$ AM

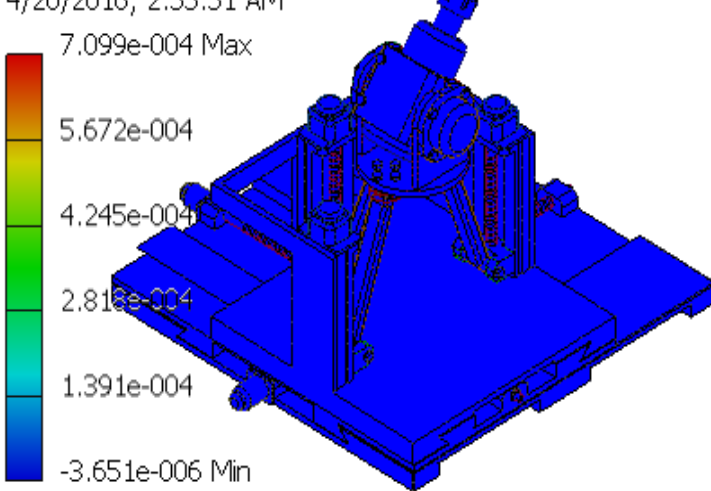

(b) First principle strain distribution

Type: 3rd Principal Strain

Unit: ul

4/20/2016, 2:57:32 AM

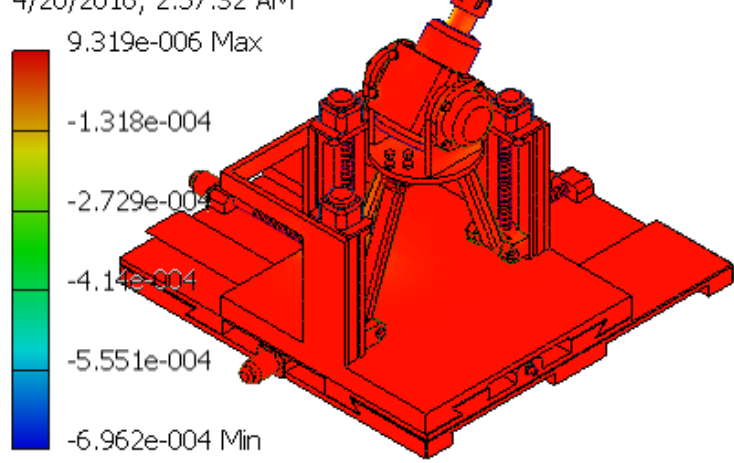

(c) Third principle strain distribution

Figure 3: Strain distribution on the hybrid kinematic machine 


\section{International Journal of Science and Research (IJSR) \\ ISSN (Online): 2319-7064}

Index Copernicus Value (2013): 6.14 | Impact Factor (2015): 6.391

Type: Displacement

Unit: $\mathrm{mm}$

$4 / 20 / 2016,2: 49: 41$ AM

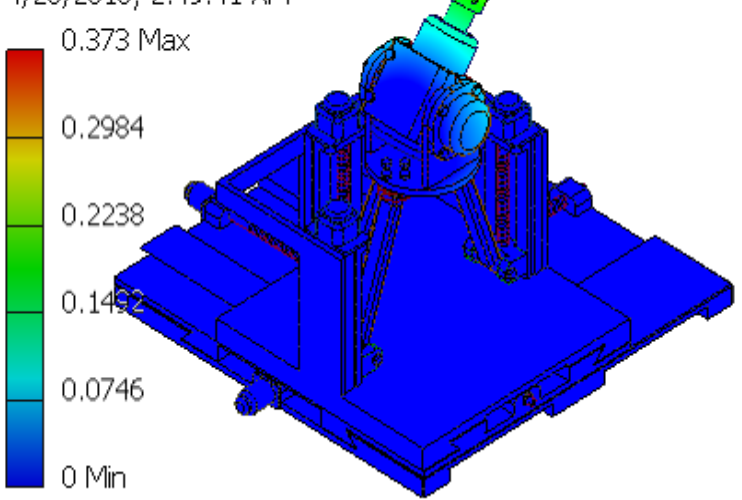

Figure 4: Total displacement

Type: Safety Factor

Unit: ul

4/20/2016, 2:59:06 AM

15 Max
12
9
6
3
1.75 Min
0

Figure 5: Factor of safety under the applied load

Table 2: Result Summary

\begin{tabular}{|c|c|c|}
\hline Name & Minimum & Maximum \\
\hline Volume & $18096500 \mathrm{~mm}^{\wedge} 3$ \\
\hline Mass & $139.596 \mathrm{~kg}$ \\
\hline Von Mises Stress & $7,99649 \times 10^{-9} \mathrm{MPa}$ & $142.562 \mathrm{MPa}$ \\
\hline 1st Principal Stress & $-30.8669 \mathrm{MPa}$ & $158.183 \mathrm{MPa}$ \\
\hline 3rd Principal Stress & $-133.992 \mathrm{MPa}$ & $45.7243 \mathrm{MPa}$ \\
\hline Displacement & $0 \mathrm{~mm}$ & $0.372959 \mathrm{~mm}$ \\
\hline Safety Factor & $1.75362 \mathrm{ul}$ & $15 \mathrm{ul}$ \\
\hline Stress XX & $-78.4663 \mathrm{MPa}$ & $66.3658 \mathrm{MPa}$ \\
\hline Stress XY & $-61.0291 \mathrm{MPa}$ & $47.253 \mathrm{MPa}$ \\
\hline Stress XZ & $-48.704 \mathrm{MPa}$ & $72.5332 \mathrm{MPa}$ \\
\hline Stress YY & $-122.452 \mathrm{MPa}$ & $85.6873 \mathrm{MPa}$ \\
\hline Stress YZ & $-40.455 \mathrm{MPa}$ & $47.0138 \mathrm{MPa}$ \\
\hline Stress ZZ & $-76.1248 \mathrm{MPa}$ & $156.771 \mathrm{MPa}$ \\
\hline Equivalent Strain & $4,62299 \times 10^{-14} \mathrm{ul}$ & $0.000653184 \mathrm{ul}$ \\
\hline 1st Principal Strain & $-3,65061 \times 10^{-6} \mathrm{ul}$ & $0.000709892 \mathrm{ul}$ \\
\hline 3rd Principal Strain & $-0.000696177 \mathrm{ul}$ & $9,31937 \times 10^{-6} \mathrm{ul}$ \\
\hline Strain XX & $-0.000398532 \mathrm{ul}$ & $0.000340584 \mathrm{ul}$ \\
\hline Strain XY & $-0.000411077 \mathrm{ul}$ & $0.000318284 \mathrm{ul}$ \\
\hline Strain XZ & $-0.000299246 \mathrm{ul}$ & $0.000488565 \mathrm{ul}$ \\
\hline Strain YY & $-0.000618451 \mathrm{ul}$ & $0.000376326 \mathrm{ul}$ \\
\hline Strain YZ & $-0.000248562 \mathrm{ul}$ & $0.000288861 \mathrm{ul}$ \\
\hline Strain ZZ & $-0.000266937 \mathrm{ul}$ & $0.000611068 \mathrm{ul}$ \\
\hline
\end{tabular}

\section{Discussions}

From the results presented in table (2) it is clear that the hybrid kinematic machine being analyzed will not fail due to excessive stress under the design loads. The stresses, strain as well as the displacements are so small to cause any failure basing on the Von Mises theory. There is a high factor of safety in all other components save for the tool shoulder which has a factor of $2 \mathrm{ul}$ hence if unexpected heavy loads are encountered, the worst case scenario is the breaking of the tool about its shoulder leaving the rest of the machine structure unaffected. This is a desirable characteristic for the application under consideration. Fig 6 shows the tool shoulder section which is subject to stress concentration. All the maximum stress values are identified to be located on this section of the mechanism.

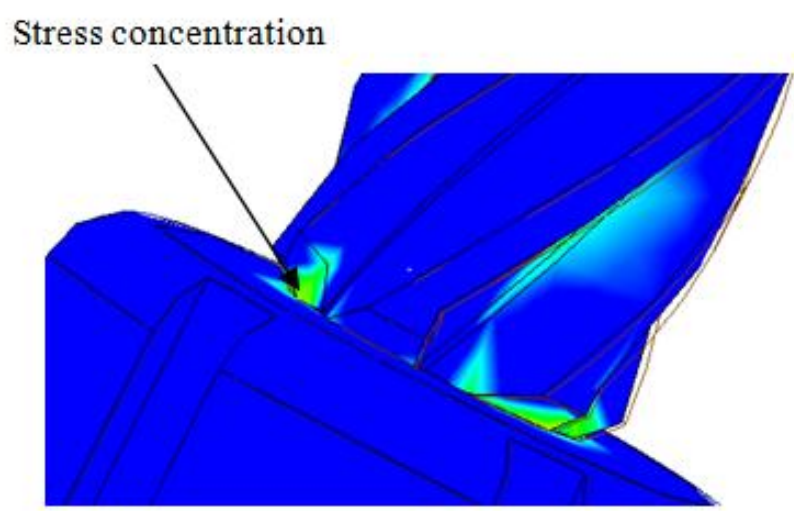

Figure 6: Stress concentration on tool shoulder

From the simulation which was conducted in this paper it can be concluded that the hybrid kinematic machine for on-site machining which was proposed in [3] is rigid enough to carry out the desired milling and drilling operation without failure however a multi-objective optimization may be necessary in order to further reduce the weight of the structure while increasing the stiffness.

\section{References}

[1] Chandrupatla, T. R. and Belegundu, A.D. Introduction to Finite Elements in Engineering, $3^{\text {rd }}$ ed, Pearson Education. (2002).

[2] Crisfield M.A, Non-Linear Finite Element Analysis of Solids and Structures, Advanced Topics, Vol 2, Wiley, 1997, pp 451.

[3] Maxwell Zvikomborero Sakutukwa, Anshul Jain, "Conceptual Design of a Six DOF Hybrid Kinematic Machine for On-Site Machining", International Journal of Science and Research (IJSR), https://www.ijsr.net/archive/v5i4/v5i4.php, Volume 5 Issue 4, April 2016, 1594 - 1597

[4] Li, Y., Zhang, E., Song, Y. and Feng, Z. (2013). "Stiffness modeling and analysis of a novel 4-DOF PKM for manufacturing large components," Chinese Journal of Aeronautics, 26(6), pp.1577-1585.

[5] Carbone, G. and Ceccarelli, M. (2004). A stiffness analysis for a hybrid parallel-serial manipulator. Robotica, 22(5), pp.567-576. 
[6] Zhang. D, Gao. Z. (2015). Performance analysis and optimization of a five-degrees-of-freedom compliant hybrid parallel micromanipulator, Robotics and Computer-Integrated Manufacturing, 34, 20-29.

[7] Radu, B., Codrean, C., Finite element modeling of thermal field developed in induction brazing of stainless steels with quasi-amorphous brazing alloys, M.T.P., IXth Edition Timişoara academic Days International Symposium, May 26-27, 2005

[8] Lin, G., Pang, L., Hu, Z. and Zhang, Y. (2016). Improving accuracy and efficiency of stress analysis using scaled boundary finite elements. Engineering Analysis with Boundary Elements, 67, pp.26-42.

[9] Singh, S. (1980). Strength of materials. New Delhi: Khanna Publishers.

\section{Author Profile}

Maxwell Zvikomborero Sakutukwa is a Post Graduate student pursuing M.Tech degree in Machine Design at (Institute of Technology and Management) I.T.M University, Gwalior, M.P, India., he is a holder of a B.Tech Honors Degree in Industrial and Manufacturing Engineering from Harare Institute of Technology, Zimbabwe which was awarded in 2012. Before university education he was trained as an apprentice Fitter and Turner by National Railways of Zimbabwe. His research interests include Computer Aided Design, Robotics and Automation.

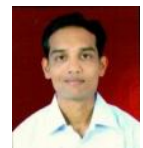

Anshul Jain is currently working as an Assistant Professor at ITM University, Gwalior. He has done his M.Tech from NIT Allahabad in CAD/CAM. He has more than three years of teaching experience. Some of his work has been presented in national and international conferences. His research interests include CAD/CAM, Robotics and Rapid Prototyping. 